\title{
Modulation of Mood and Cognitive Performance Following Acute Administration of Single Doses of Melissa Officinalis (Lemon Balm) with Human CNS Nicotinic and Muscarinic Receptor-Binding Properties
}

\author{
DO Kennedy*,', G Wake', S Savelev ${ }^{3}$, NTJ Tildesley', EK Perry², KA Wesnes ${ }^{1,4}$ and AB Scholey' \\ 'Human Cognitive Neuroscience Unit, Division of Psychology, Northumbria University, Newcastle upon Tyne, UK; ${ }^{2}$ Centre Development in Clinical \\ Brain Aging, MRC Building, Newcastle General Hospital, Newcastle upon Tyne, UK; ${ }^{3}$ Department of Agricultural \& Environmental Science, \\ University of Newcastle upon Tyne, UK; ${ }^{4}$ Cognitive Drug Research Ltd, Portman Road, Reading, UK
}

\begin{abstract}
Melissa officinalis (Lemon balm) is a herbal medicine that has traditionally been attributed with memory-enhancing properties, but which is currently more widely used as a mild sedative and sleep aid. In a previous study it was demonstrated that a commercial Melissa extract led to dose-specific increases in calmness, and dose-dependent decrements in timed memory task performance. However, the extract utilized in that study did not exhibit in vitro cholinergic receptor-binding properties. The current study involved an initial screening of samples of $M$. officinalis for human acetylcholinesterase inhibition and cholinergic receptor-binding properties. The cognitive and mood effects of single doses of the most cholinergically active dried leaf were then assessed in a randomized, placebo-controlled, double-blind, balanced crossover study. Following the in vitro analysis, 20 healthy, young participants received single doses of 600, 1000, and I600 mg of encapsulated dried leaf, or a matching placebo, at 7-day intervals. Cognitive performance and mood were assessed predose and at I, 3, and $6 \mathrm{~h}$ postdose using the Cognitive Drug Research computerized assessment battery and Bond-Lader visual analog scales, respectively. In vitro analysis of the chosen extract established $I_{50}$ concentrations of 0.18 and $3.47 \mathrm{mg} \mathrm{ml}^{-1}$, respectively, for the displacement of [ ${ }^{3} \mathrm{H}$ ](N)-nicotine and $\left[{ }^{3} \mathrm{H}\right]-(\mathrm{N})$-scopolamine from nicotinic and muscarinic receptors in human cerebral cortex tissue. However, no cholinesterase inhibitory properties were detected. The most notable cognitive and mood effects were improved memory performance and increased 'calmness' at all postdose time points for the highest (1600 mg) dose. However, while the profile of results was overwhelmingly favorable for the highest dose, decrements in the speed of timed memory task performance and on a rapid visual information-processing task increased with decreasing dose. These results suggest that doses of Melissa officinalis at or above the maximum employed here can improve cognitive performance and mood and may therefore be a valuable adjunct in the treatment of Alzheimer's disease. The results also suggest that different preparations derived from the same plant species may exhibit different properties depending on the process used for the sample preparation.
\end{abstract}

Neuropsychopharmacology (2003) 28, I87|-|88I, advance online publication, 23 July 2003; doi: I 0.I038/sj.npp. I 300230

Keywords: cholinergic; nicotinic; muscarinic; Melissa officinalis; memory; mood

\section{INTRODUCTION}

Melissa officinalis (Lemon balm) has a documented medicinal history extending back to the 'Materia Medica' in approximately $50-80 \mathrm{BC}$. It gained widespread usage throughout Europe by the middle ages (Koch-Heitzmann and Schultze, 1988), with medicinal use during this early

\footnotetext{
*Correspondence: Dr D Kennedy, Human Cognitive Neuroscience Unit, Division of Psychology, University of Northumbria, Newcastle upon Tyne NEI 8ST, UK, Tel.: + 43 191 227 4468, Fax: +43 191 227 3190, E-mail: david.kennedy@unn.ac.uk

Received 02 October 2002; revised 12 February 2003; accepted 30 April 2003

Online publication: I5 May 2003 at http://www.acnp.org/citations/ Npp05 I 502365/default.pdf
}

epoch including a recommendation by Paracelsus (14931541) that balm would completely revivify a man, and as an indication for 'all complaints supposed to proceed from a disordered state of the nervous system' (Grieve, 1931). Several herbal apothecaries of the time also attributed balm tea not only with general beneficial effects upon the brain but also specific mnemonic improvements (Coghan, 1584; Evelyn, 1699).

Contemporary reports suggest that, in addition to possessing spasmolytic and antibacterial properties, $M$. officinalis can modulate a number of behavioral measures, with indications including administration as a mild sedative, in disturbed sleep, and in the attenuation of the symptoms of nervous disorders, including the reduction of excitability, anxiety, and stress (Kommission E Monograph, 
1984; Bisset and Wichtl, 1994). In keeping with its long history of safe usage, no adverse side effects have so far been reported for the herb (Wong et al, 1998).

M. officinalis is predominantly sold in combination with other herbs, including 49 products that contain Lemon balm in the German pharmaceutical industry's Rote liste (2001) drug catalog. It is most often combined with Valeriana officinalis, and this combination has been reported to have as positive an effect on the sleep quality of poor sleepers as $0.125 \mathrm{mg}$ of Triazolam (Dressing et al, 1992). Similarly, a placebo-controlled trial found significant improvements in the quality of sleep during 30 days of treatment with $600 \mathrm{mg} \mathrm{day}^{-1}$ of a Melissa-Valerian combination (Cerny and Schmid, 1999).

Several studies suggest specific sedative, anti-agitation, and 'calming' effects of $M$. officinalis alone. These include, in mice, a reduction in spontaneous movement following administration of both the whole volatile oil of melissa and individual isolated terpenes of the extract (Wagner and Sprinkmeyer, 1973), and reductions in behavioral activity in exploratory and aversive situations following administration of a hydro-alcoholic extract of melissa. In the latter study, the extract also increased pentobarbital-induced sleep parameters (Soulimani et al, 1991).

A recent double-blind, placebo-controlled study examined the effect of $M$. officinalis essential oil aromatherapy on ratings of agitation and quality of life of 71 patients suffering from severe dementia (Ballard et al, 2002). Following 4 weeks of treatment, patients in the active treatment group were rated, in comparison to the placebo group, as being less agitated, less socially withdrawn, and as engaging in more time spent in constructive activities in comparison to the placebo group.

Behavioral consequences such as these may be attributed to a number of possible active components of the dried leaf and essential oil of the herb. Constituents that have been identified include a number of monoterpenoid aldehydes (including citronellal, neral, and geranial) (Carnat et al, 1998), flavonoids, and polyphenolic compounds, most notably rosmarinic acid (Carnat et al, 1998; Hohmann et al, 1999) and monoterpene glycosides (Mulkens et al, 1985).

It has previously been suggested, on the basis of a retrospective review of the historical role of a number of European plant species in the enhancement of memory, that M. officinalis and Salvia officinalis (Sage), another plant in the Labiatae family, might potentially provide novel natural treatments for Alzheimer's disease (Perry et al, 1999). This approach has generated research showing that $M$. officinalis exhibits central nervous system acetylcholine receptor activity, including nicotinic (Perry et al, 1996; Wake et al, 2000) and muscarinic (Wake et al, 2000) binding properties in human cerebral cortex tissue. Perry et al's (1996) investigation also suggested that fresh, but not dried, $M$. officinalis leaf possessed modest human brain acetylcholinesterase (AChE) inhibitory properties. The cholinergic receptor-binding properties in particular suggest the possibility that $M$. officinalis may provide a potential treatment for the cholinergic dysfunction in Alzheimer's disease, while contemporary use of the herb as a mild sedative may provide a concomitant beneficial effect on the severe agitation often associated with severe dementia. Additionally, its antioxidant properties (Hohmann et al,
1999; Mantle et al, 2000) suggest that Melissa may also provide some protection against the putative etiological free radical damage in dementia.

A first investigation of the possibility of modulation of cognitive performance and mood following oral administration of $M$. officinalis was recently reported from this laboratory (Kennedy et al, 2002b). The acute dose (three separate doses plus placebo), multiple time-point $(1,2.5,4$, and $6 \mathrm{~h}$ postdose) experiment showed that the ingestion of single doses of a commercial $M$. officinalis extract by healthy young volunteers was associated with striking dosedependent impairments on a 'Quality of Memory' measure derived by factor analysis from the Cognitive Drug Research (CDR) computerized assessment battery. More specifically, decrements were most pronounced for all the three doses utilized on two timed memory tasks (delayed word recognition and a spatial memory task). The overall pattern of results also indicated that, while the memory task decrements increased with dose, the lowest dose $(300 \mathrm{mg}$ ) engendered increased 'calmness' at the first two postdose testing sessions ( 1 and $2.5 \mathrm{~h}$ ), and the middle dose $(600 \mathrm{mg}$ ) led to improved performance on attention tasks. The highest dose, however, was not associated with any benefits, and led to the most pronounced decrements on the memory tasks along with reduced 'alertness' at all postdose testing sessions. This pattern of results is broadly in line with the contemporary role of $M$. officinalis as a calming agent and mild sedative, but it is disappointing in as much as it is not in keeping with beneficial modulation of cholinergic activity. However, an in vitro analysis conducted after the behavioral experiment showed that, unlike previous such investigations (Perry et al, 1996; Wake et al, 2000), the extract in question showed negligible displacement of $\left[{ }^{3} \mathrm{H}\right]-$ (N)-nicotine from nicotinic receptors, and comparatively low displacement of $\left[{ }^{3} \mathrm{H}\right]-(\mathrm{N})$-scopolamine from muscarinic receptors.

This leaves open the question of the cognitive and mood effects of a cholinergically active $M$. officinalis treatment, which ideally may engender increased calmness with concomitant improvements in cognitive performance.

The current study therefore comprised two distinct phases. In the first, eight separate acquisitions of dried $M$. officinalis leaf, with known provenance, were assessed for AChE inhibition and both nicotinic and muscarinic receptor-binding properties in human post-mortem occipital cortex tissue. In the second phase, the cognitive and mood effects of administration of the most 'cholinergically active' melissa acquisition were assessed in healthy young volunteers in a multiple-dose, multiple time-point, doubleblind, placebo-controlled, balanced crossover experiment. As with a series of previous studies looking at the cognitive effects of herbal remedies (Kennedy et al, 2000, 2001a, b, $2002 a, b)$, the primary outcomes were a 'Quality of Memory' measure and the five cognitive factors ('Secondary Memory', 'Working Memory', 'Speed of Memory', 'Speed of Attention', and 'Accuracy of Attention') that can be derived from the complete CDR computerized assessment battery (Wesnes et al, 2000). An additional 'cholinergically sensitive' (Wesnes and Warburton, 1984; Wesnes et al, 1990) rapid visual information processing task (RVIP) was also included. Mood was assessed concurrently with BondLader visual analogue scales (Bond and Lader, 1974). 


\section{MATERIALS AND METHODS}

\section{In Vitro Analysis}

\section{Nicotinic and muscarinic receptor-binding analysis}

Meliss a extract preparation: Eight acquisitions of highquality dried M. officinalis leaf were made from commercial sources. All leaves were of known provenance, and had been organically grown in Europe, with the exception of Sample 1. They were harvested prior to flowering.

The M. officinalis samples were prepared for two separate analyses. In the first analysis, a crude ethanolic extract of the whole herb was assessed, in separate assays, for receptor binding to human cortex nicotinic and muscarinic receptors. In the second analysis, a moderately polar fraction (containing terpenoids and phenolic materials) was isolated for muscarinic analysis, and a basic fraction (ionizable basic materials) was isolated for nicotinic analysis. The fractionation served two purposes. Firstly, it was intended to confirm that any displacement properties of the crude extract were receptor specific, as opposed to being a result of adherence by incidental plant components hindering the access of the radiolabels. Secondly, it served to highlight inhibitory or synergistic properties of the crude extract by demonstrating whether the activity in the fractions was less or greater than that of the whole extract.

Ethanolic extracts: Ethanolic extracts were prepared by allowing coarsely pulverized $10 \mathrm{~g}$ portions of the various Melissa acquisitions to macerate for 7 days in $80 \%$ ethanol (aqueous) at $4{ }^{\circ} \mathrm{C}$ in darkness. The ethanolic solutions were then decanted from the extracted leaf residues, filtered through Whatman No. 1 filter papers and stored at $-20^{\circ} \mathrm{C}$ in glass-stoppered conical flasks. For assay, the extracts were diluted 1:1 with $80 \%$ ethanol to bring the working solution to a concentration of $100 \mathrm{mg} \mathrm{ml}^{-1}$ and the assay concentration to $10 \mathrm{mg} \mathrm{ml}^{-1}$.

Extract fractionation: Coarsely pulverized $20 \mathrm{~g}$ samples of the various $M$. officinalis acquisitions were allowed to macerate for 7 days in $200 \mathrm{ml}$ aliquots of $100 \%$ methanol. The liquors were filtered from the leaf materials, and evaporated to $1 / 5$ th volume on a Buchi rotary evaporator. The concentrated extracts were stored in their evaporating flasks at $-20^{\circ} \mathrm{C}$. The recovered solvent plus fresh methanol to make up $200 \mathrm{ml}$ solvent volumes were added to the herb residues, which were then allowed to macerate a further $24 \mathrm{~h}$, after which the methanolic liquors were decanted from the leaf materials, filtered, added to the existing concentrates, and reduced in volume on the rotary evaporator.

The $24 \mathrm{~h}$ extraction and evaporation cycles were carried out five times after the initial 7-day extraction. The final volumes of concentrated extracts were approximately $50 \mathrm{ml}$.

The methanolic melissa extracts were fractionated using differences in $\mathrm{pH}$ and hydrophobicity. Each extract was separated into a moderately polar fraction (terpenoids and phenolic materials) for muscarinic analysis, and a basic fraction (ionizable basic materials) for nicotinic analysis. Each fraction was concentrated to approximately $10 \mathrm{ml}$, transferred to weighed sample vials, evaporated to dryness on the rotary evaporator, weighed and stored at $-20^{\circ} \mathrm{C}$ until required for assay. For the assays, moderately polar fractions were prepared as $10 \mathrm{mg} \mathrm{ml}^{-1}$ solutions in $80 \%$ ethanol and basic fractions as $2 \mathrm{mg} \mathrm{ml}^{-1}$ solutions in the same solvent.

Preparation of brain membranes: Human cortex from the occipital lobe (obtained from the Newcastle General Hospital Brain Bank) was homogenized and prepared as described by Wake et al (2000).

Nicotinic and muscarinic displacement assays: The displacement of radiolabeled $\left[{ }^{3} \mathrm{H}\right]$-nicotine and $\left[{ }^{3} \mathrm{H}\right]$ scopolamine from the tissue homogenates by both the crude ethanolic extracts and methanolic fractions prepared from the $M$. officinalis samples was undertaken using the methods described in detail by Wake et al (2000).

Human AChE inhibition: Ethanolic extracts of the dried leaf samples and post-mortem samples of normal human brain tissue were prepared using the methodology described in Perry et al (1996). AChE activity was measured in homogenates using the spectrophotometric method of Ellman et al (1961) following the methodology of Perry et al (1996).

\section{Cognitive Assessment}

Participants. A total of 14 female and six male undergraduate volunteers (mean age 19.2 years, age range 18-23) took part in the study, which was approved by the Joint Ethics Committee of Newcastle and North Tyneside Health Authority and was carried out in accordance with the Declaration of Helsinki. Prior to participation, each volunteer signed an informed consent form and completed a medical health questionnaire. All participants reported that they were in good health, and were taking no illicit social drugs. Additionally, they were free of any 'over-thecounter' or prescribed medications, with the exception, for some female volunteers, of the contraceptive pill. Owing to possible confounding effects on CNS cholinergic status, smokers were excluded from the study. All participants abstained from caffeine-containing products throughout each study day, and alcohol for a minimum of $12 \mathrm{~h}$ prior to the first testing session of the morning.

CDR computerized assessment battery. The CDR computerized assessment battery has been used in hundreds of European and North American drug trials, and has been shown to be sensitive to acute cognitive improvements (eg Moss et al, 1998; Scholey et al, 1999) as well as impairments with a wide variety of substances (eg Ebert et al, 1998; O'Neill et al, 1995).

A tailored version of the CDR battery was used. This has previously been found to be sensitive to modulation of cognitive function as a consequence of acute ingestion of $M$. officinalis (Kennedy et al, 2002b), Ginkgo biloba (Kennedy et al, 2000, 2002a), and Panax ginseng (Kennedy et al, 2001a, 2002a), and acute and chronic administration of a $G$. biloba/P. ginseng combination (Kennedy et al, 2001b, 2002a; Wesnes et al, 1997, 2000). In the case of the current study, the additional RVIP task was included in the battery. The running order of the tasks is illustrated in Figure 2. The 
selection of computer-controlled tasks from the system was administered with randomly ordered parallel forms of the tests being presented at each testing session. Presentation was via desktop computers with high-resolution VGA color monitors, and, with the exception of written word recall tests, all responses were recorded via two-button (YES/NO) response boxes. The entire selection of tasks took approximately $20 \mathrm{~min}$ to perform.

Tests were administered in the following order:

Word presentation: A total of 15 words, matched for frequency and concreteness, were presented in random order on the monitor for the participant to remember. Stimulus duration was $1 \mathrm{~s}$, as was the interstimulus interval.

Immediate word recall: The participant was allowed $60 \mathrm{~s}$ to write down as many of the words as possible. The task was scored as the number of words correct and the resulting score was converted into a percentage.

Picture presentation: A series of 20 photographic images of everyday objects and scenes were presented on the monitor at the rate of 1 every $3 \mathrm{~s}$, with a stimulus duration of $1 \mathrm{~s}$, for the participant to remember.

Simple reaction time: The participant was instructed to press the 'YES' response button as quickly as possible, every time the word 'YES' was presented on the monitor. In all, 50 stimuli were presented with an interstimulus interval that varied randomly between 1 and $3.5 \mathrm{~s}$. Reaction times were recorded in $\mathrm{ms}$.

Digit vigilance task: A target digit was randomly selected and constantly displayed to the right of the monitor screen. A series of digits was presented in the center of the screen at the rate of $80 \mathrm{~min}^{-1}$ and the participant was required to press the 'YES' button as quickly as possible every time the digit in the series matched the target digit. The task lasted $1 \mathrm{~min}$ and there were 15 stimulus-target matches. Task measures were accuracy (\%), reaction time (ms), and number of false alarms.

Choice reaction time: Either the word 'NO' or the word 'YES' was presented on the monitor and the participant was required to press the corresponding button as quickly as possible. There were 50 trials, of which the stimulus word was chosen randomly with equal probability, with a randomly varying interstimulus interval of between 1 and $3.5 \mathrm{~s}$. Reaction times (ms) and accuracy (\%) were recorded.

Spatial working memory: A pictorial representation of a house was presented on the screen with four of its nine windows lit. The participant was instructed to memorize the position of the illuminated windows. In 36 subsequent presentations of the house, one of the windows was illuminated and the participant decided whether or not this matched one of the lighted windows in the original presentation. The participants entered their response by pressing the 'YES' or 'NO' response button as quickly as possible. The mean reaction times were measured in $\mathrm{ms}$, and the accuracies of responses to both original and novel (distracter) stimuli were recorded as percentages that were used to derive a '\% greater than chance performance' score (percentage of original targets + percentage of novel targets correctly identified - 100).

Numeric working memory: Five digits were presented sequentially for the participant to hold in memory. This was followed by a series of 30 probe digits, for each of which the participant decided whether or not it had been in the original series and pressed the 'YES' or 'NO' response button as appropriate as quickly as possible. This was repeated two further times with different stimuli and probe digits. The mean reaction times were measured in ms, and the accuracies of responses to both original and novel (distracter) stimuli were recorded as percentages that were used to derive a ' $\%$ greater than chance performance' score as above.

Delayed word recall: The participant was again given $60 \mathrm{~s}$ to write down as many of the words as possible. The task was scored for number of words correct and the resulting score was converted into a percentage.

Delayed word recognition: The original words plus 15 distracter words were presented one at a time in a randomized order. For each word, the participant indicated whether or not he recognized it as being included in the original list of words by pressing the 'YES' or 'NO' button as appropriate and as quickly as possible. The mean reaction times were measured in $\mathrm{ms}$, and the accuracies of responses to both original and novel (distracter) stimuli were recorded as percentages that were used to derive a ' $\%$ greater than chance performance' score as above.

Delayed picture recognition: The original pictures plus 20 distracter pictures were presented one at a time in a randomized order. For each picture, participants indicated whether or not it was recognized as being from the original series by pressing the 'YES' or 'NO' button as appropriate and as quickly as possible. The mean reaction times were measured in ms, and the accuracies of responses to both original and novel (distracter) stimuli were recorded as percentages that were used to derive a '\% greater than chance performance' score as above.

Primary cognitive outcome measures: The above measures were collapsed into the 'quality of memory' measure and five cognitive outcome factors derived from the battery by a factor analysis conducted by Wesnes et al (2000). These measures have been utilized in a number of studies, including several assessing the cognitive effects of herbal remedies (Kennedy et al, 2000, 2001a, b, 2002a, b; Wesnes et al, 1997, 2000). The original factor analysis of data from the battery is described in detail in Wesnes et al (2000). The contribution of each individual task outcome to the outcome factors is included in Figure 1. The factors are described below.

Memory factors: 'Quality of Memory' measure: derived by combining the 'Secondary Memory' and 'Working Memory' factor scores (see below).

'Secondary Memory' factor: derived by combining the percentage accuracy scores (adjusted for proportions of novel and original stimuli where appropriate) from all of the secondary memory tests - delayed word recognition, delayed picture recognition, immediate word recall, and delayed word recall (with adjustments to the total \% correct for errors and intrusions on the latter two tasks). A 100\% accuracy across the four tasks would generate a maximum score of 400 on this index.

'Working Memory' factor: derived by combining the percentage accuracy scores from the two working memory tests - spatial working memory and numeric working memory; $100 \%$ accuracy across the two tasks would generate a maximum score of 200 on this index. 


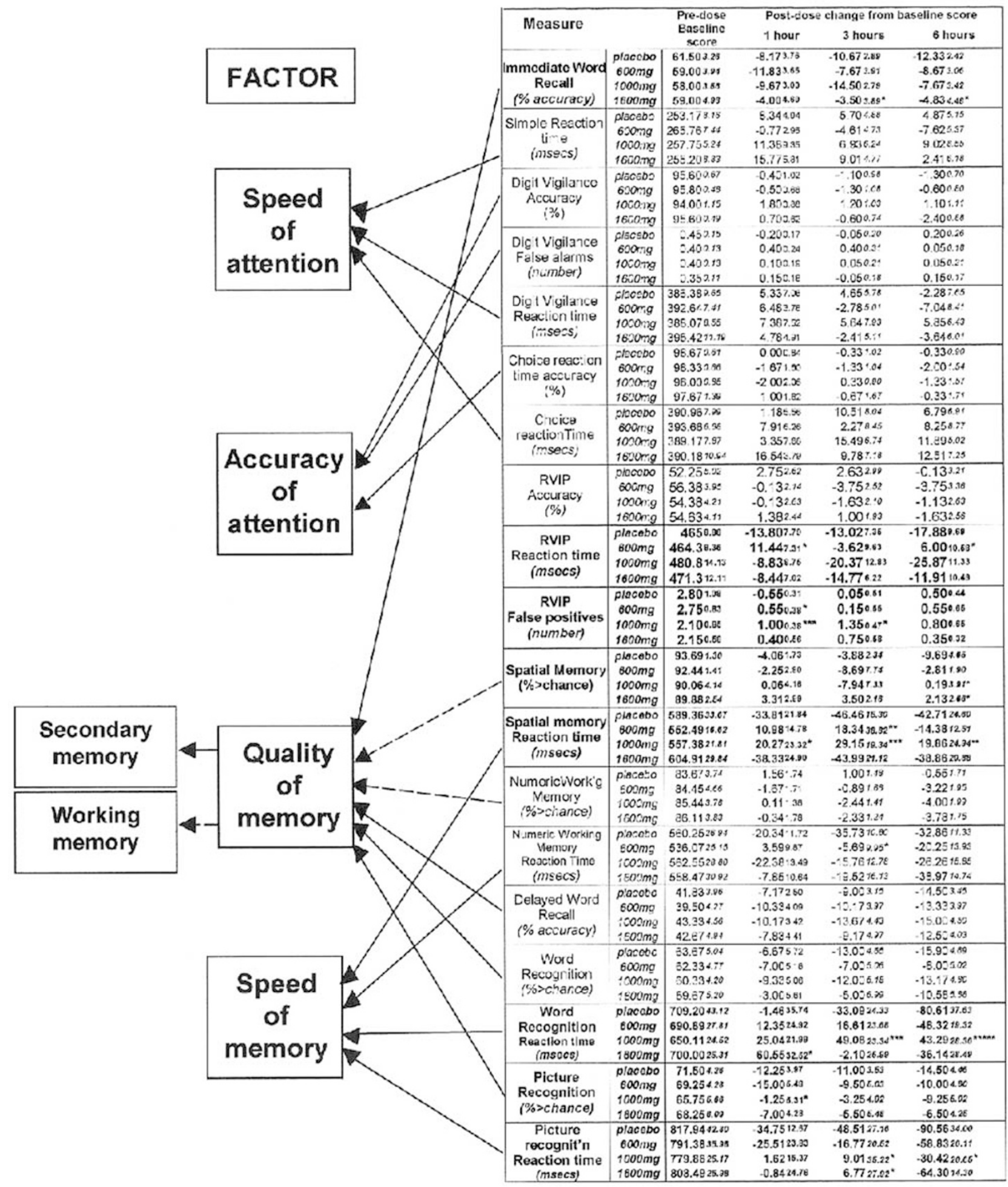

Figure I Effects of M. officinalis on the individual task outcome measures from the CDR battery. Mean baseline and change from baseline scores (with standard errors) are presented. Tasks are displayed in order of completion with a diagrammatic representation of which cognitive factor they contribute to on the left. Asterisks denote the results of planned comparisons on the measures (which are shown in bold italics) that showed a main effect of treatment or trend towards a main effect on the initial ANOVA ( $* P=0.05$; ** $P=0.01$; *** $P=0.005$; **** $P=0.00$ I; ***** $P=0.0005$, compared to placebo).

'Speed of Memory' factor: derived by combining the reaction times of the four computerized memory tasksnumeric working memory, spatial memory, delayed word recognition, and delayed picture recognition (units are summed milliseconds for the four tasks).
Attention factors: 'Speed of Attention' factor: derived by combining the reaction times of the three attentional tasks-simple reaction time, choice reaction time, and digit vigilance (units are summed milliseconds for the three tasks). 
'Accuracy of Attention' factor: derived by calculating the combined percentage accuracy across the choice reaction time and digit vigilance tasks with adjustment for false alarms from the latter test. A $100 \%$ accuracy across the two tasks would generate a maximum score of 100 .

Rapid visual information processing task (RVIP): This task has been widely used to study the cognitive effects of psychotropic drugs, and has been shown to be sensitive to cholinergic modulation (eg Wesnes and Warburton, 1984; Wesnes et al, 1990). The participant monitors a continuous series of digits for targets of three consecutive odd or three consecutive even digits. The digits are presented at the rate of $100 \mathrm{~min}^{-1}$ and the participant responds to the detection of a target string by pressing the 'yes' response button as quickly as possible. The task is continuous and lasts for $5 \mathrm{~min}$, with eight correct target strings being presented in each minute. The task is scored for percentage of target strings correctly detected, average reaction time for correct detections, and number of false alarms. This task was not included in the original factor analysis (Wesnes et al, 2000) and is therefore analyzed separately here.

Subjective mood measure: The Bond-Lader Visual Analog Scales (Bond and Lader, 1974), consisting of 16 $100 \mathrm{~mm}$ visual analog scales anchored by antonyms (eg Alert-Drowsy, Lethargic-Energetic, etc), were combined as recommended by the authors to form three mood factors: alertness, calmness, and contentedness.

Treatments: On each study day, participants received eight capsules that were of identical appearance on each occasion. The individual capsules contained either an inert placebo, or $200 \mathrm{mg}$ of the powdered, dried M. officinalis leaf selected on the basis of the results from the in vitro analysis (see 'In vitro analysis' results below). Depending on the condition to which the participant was allocated on that particular day, the combination of capsules corresponded to a dose of either 0 (placebo), 600, 1000, or $1600 \mathrm{mg}$ of $M$. officinalis leaf. To maintain the double blind, a disinterested third party was responsible for preparing treatments and the code remained unbroken until the initial statistical analysis had been completed. All treatments were identical in appearance and scent.

Procedure: Each participant was required to attend a total of five study days that were conducted 7 days apart, to ensure a sufficient washout between conditions. Testing took place, commencing at the same time on each day, in a suite of laboratories with participants visually isolated from each other.

On arrival at their first session on the first day, participants were randomly allocated to a treatment regime using a Latin square design that counterbalanced the order of treatments across the four active days of the study.

The first day was identical to the following four, except that no treatment (active or placebo) was offered, to allow familiarization with the test battery and procedure. Data from the four sessions of this practice day were not included in any analysis. Each active study day comprised four identical testing sessions. The first was a predose testing session that established baseline performance for that day, and was immediately followed by the day's treatment on days $2-5$. Further testing sessions began at 1,3 , and $6 \mathrm{~h}$ following consumption of the day's treatment.

Each testing session comprised completion of the BondLader visual analog scales, and the CDR test battery.

Statistics: Scores on the individual task outcomes, the four primary factors, and the two memory subfactors were analyzed as 'change from baseline' using the Minitab statistical package.

Prior to carrying out planned comparisons, an analysis of variance (ANOVA) (General Linear Model), with terms fitted to the model for dose, visit, dose $\times$ visit, and subject (Kirk, 1968), was carried out to identify the main effects and interaction effects on each measure. The primary statistical analysis of the 'change from baseline' data for each measure followed the recommendation of Keppel (1991), and was carried out using planned comparisons, utilizing $t$-tests with the mean squares for 'Dose*Time* Subjects' from an omnibus ANOVA as an error term. At each time point (1, 3 , and $6 \mathrm{~h}$ postdose), data from the placebo condition were compared to those for each of the three doses of $M$. officinalis $(600,1000$, and $1600 \mathrm{mg})$. To ensure the overall Type I error protection level, only those planned comparisons associated with measures that generated a significant main effect or interaction effect, or a trend towards the same, on the initial ANOVA are reported. Furthermore, all testing was two-tailed, comparisons were strictly planned prior to the study, were restricted to the number of conditions minus one at each time point, and only probabilities associated with these preplanned comparisons were calculated.

\section{RESULTS}

\section{In Vitro Analysis}

Cholinergic receptor binding. $\mathrm{IC}_{50}$ values for the displacement of radio-labeled $\left[{ }^{3} \mathrm{H}\right]$-nicotine and $\left[{ }^{3} \mathrm{H}\right]$-scopolamine from human occipital cortex tissue are shown in Table 1. The relative activity is ranked in order of effectiveness for both nicotine and scopolamine displacement, by both the whole ethanolic extract and the active fractions. In the case of the fractions, in order to make a valid comparison between samples, the rank reflects both displacement and the comparative yield of the fraction (data not shown) from the leaf for each sample.

The primary indicator of relevant activity is displacement by the whole ethanolic melissa extract, which reflects the combined effects of coligands, synergists, and binding inhibitors present in the dried leaf. However, in order to validate this activity, displacement by the basic fraction or moderately polar fraction must also be substantial for any given sample. This indicates that the demonstrated displacement is due to a direct influence on the receptorbinding site rather than an indirect property of the extract (eg interference with binding). All of the assessed samples demonstrated substantial levels of displacement of radioligand from muscarinic receptors.

However, in the case of nicotinic receptors, samples 5, 7, and 8 were excluded from further consideration on the 
Table I $\quad \mathrm{CC}_{50}$ Values for Displacement of Radio-Labeled $\left[{ }^{3} \mathrm{H}\right]$-Nicotine and $\left[{ }^{3} \mathrm{H}\right]$-Scopolamine from Human Occipital Cortex Tissue for the M. Officinalis Samples

\begin{tabular}{|c|c|c|c|c|c|c|c|c|}
\hline \multirow[b]{2}{*}{$\begin{array}{l}\text { Melissa } \\
\text { sample }\end{array}$} & \multicolumn{4}{|c|}{ Ethanol extract of whole herb } & \multicolumn{2}{|c|}{ Basic fraction } & \multicolumn{2}{|c|}{ Moderately polar fraction } \\
\hline & $\begin{array}{c}\mathrm{IC}_{50}\left(\mathrm{mg} \mathrm{ml}^{-1}\right) \\
\text { nicotine } \\
\text { displacement }\end{array}$ & Rank & $\begin{array}{c}\mathrm{IC}_{50}\left(\mathrm{mg} \mathrm{mI}^{-1}\right) \\
\text { scopolamine } \\
\text { displacement }\end{array}$ & Rank & $\begin{array}{c}\mathrm{IC}_{50}\left(\mu \mathrm{g} \mathrm{mI}^{-1}\right) \\
\text { nicotine } \\
\text { displacement }\end{array}$ & $\begin{array}{c}\text { Rank } \\
\text { yield } / I C_{50}\end{array}$ & $\begin{array}{c}\mathrm{IC}_{50}\left(\mu \mathrm{g} \mathrm{ml}^{-1}\right) \\
\text { scopolamine } \\
\text { displacement }\end{array}$ & $\begin{array}{c}\text { Rank } \\
\text { yield/IC }\end{array}$ \\
\hline । & 0.18 & I & 3.47 & 4 & 8.6 & 5 & 162.9 & 5 \\
\hline 2 & 0.23 & 2 & 3.08 & 3 & 7.9 & 5 & 85.5 & 3 \\
\hline 3 & 0.37 & 3 & 2.69 & 2 & 7.5 & 4 & 143.4 & 4 \\
\hline 4 & 0.40 & 6 & 3.5 & 6 & 4.2 & I & |34.| & 7 \\
\hline 5 & - & - & 1.46 & I & 4.0 & 2 & 102 & 2 \\
\hline 6 & 1.12 & 4 & 3.48 & 5 & 10.0 & 5 & 102.6 & I \\
\hline 7 & 3.16 & 5 & 3.98 & 7 & - & - & 160.8 & 8 \\
\hline 8 & - & - & 4.31 & 8 & 8.0 & 3 & 104.6 & 6 \\
\hline
\end{tabular}

The rank of each sample's comparative activity (adjusted for comparative yield) is also shown for both the whole ethanolic extract and the methanolic fractions.

basis of an interference pattern on the binding curve (data not shown) of either the ethanolic extract or basic fraction (a sigmoidal dose-response curve is indicative of genuine receptor interaction). Of the remaining samples 1,2 , and 3 , all exhibited $\mathrm{IC}_{50}$ values suggesting relatively high displacement of both nicotine and scopolamine. Reference to their respective binding curves suggested that sample 1 had the most favorable profile, with sigmoidal dose-response curves for both fractions. This sample was taken forward into the behavioral experiment.

AChE inhibition: None of the extracts from the eight samples of dried $M$. officinalis exhibited any human AChE inhibitory properties, with zero percent inhibition of the enzyme at a final assay concentration of $0.25 \mathrm{mg} \mathrm{ml}^{-1}$.

\section{Cognitive Assessment}

Baseline scores. Prior to analysis of change from baseline data, mean pre-dose raw baseline scores for all four conditions (placebo, 600, 1000, and $1600 \mathrm{mg}$ M. officinalis) for each primary outcome (cognitive factor scores, RVIP scores, and Mood scale scores) were subjected to a one-way, repeated-measures ANOVA. There were no significant differences on any measure.

Individual task outcome measures: Task outcomes (in chronological order), a diagrammatic representation of which factor they contribute to, and performance data on the individual task outcome measures are presented in Figure 1. Results on individual task outcomes are described in relation to the overall factor to which they contribute below (memory task results are presented with the relevant factor, that is, 'Secondary' or 'Working' memory). Results on the RVIP are described separately below.

Cognitive factor outcome measures: The mean raw baseline scores and change from baseline scores for each condition across each session are presented in the tables and graphs of Figure 2.

Quality of memory measure: There was a significant main effect of treatment on the performance of the 'quality of memory' measure $(\mathrm{F}(3,209)=2.95, P=0.034)$. Planned comparisons of change from baseline data revealed that following the highest dose $(1600 \mathrm{mg})$ of melissa, participants performed significantly better than placebo across the memory tasks at both the 3 - and 6-h testing sessions $(3 \mathrm{~h}$ $(t(114)=2.35, P=0.02)$ and $6 \mathrm{~h}(t(114)=3, P=0.003))$. The same dose also evinced a trend towards improved performance at the 1 -h testing session $(t(114)=1.7$, $P=0.09$ ). Performance was also improved in comparison to placebo for the $600 \mathrm{mg}$ condition at the last testing session $((t(114)=2.05, P=0.042)$.

Secondary memory factor: While the initial analysis did not show any significant difference on this factor, there were trends towards improved performance on both the immediate word recall $(\mathrm{F}(3,209)=2.17, P=0.09)$ and picture-recognition tasks $(\mathrm{F}(3,209)=2.24, \quad P=0.08)$. Planned comparisons showed that on the former task, performance was significantly improved in comparison to placebo at the 3- and 6-h testing sessions for the $1600 \mathrm{mg}$ dose $\quad((t) 114)=2.04, \quad P=0.043) \quad$ and $\quad(t(114)=2.14$, $P=0.035)$, respectively). On the picture-recognition task, performance was improved for the $1000 \mathrm{mg}$ dose at $1 \mathrm{~h}$ postdose $(t(114)=2.42, P=0.017)$, with trends towards improvement for the same dose at $3 \mathrm{~h} \quad(t(114)=1.7$, $P=0.09)$ and for the $1600 \mathrm{mg}$ dose at $6 \mathrm{~h}$ postdose $(t(114)=1.76, P=0.08)$.

Working memory factor: There were no significant differences on the initial ANOVA for the working memory factor. However, the initial analysis of the single task outcomes showed a trend towards improved performance on the spatial memory task $(\mathrm{F}(3,209)=2.54, P=0.057)$. Reference to the mean scores suggested that performance following the $1600 \mathrm{mg}$ dose was consistently improved across the testing sessions, with planned comparisons showing that this reached significance at the last testing session $(t(114)=2.56, P=0.012)$. The $1000 \mathrm{mg}$ condition also outperformed the placebo condition at the 6-h testing session $(t(114)=2.14, P=0.034)$.

Speed of memory factor: There was a significant main effect of treatment on the speed of memory factor $(\mathrm{F}(3,209)=7.04, P<0.001)$. Planned comparisons revealed 


\begin{tabular}{|c|c|c|c|c|c|}
\hline \multirow[b]{2}{*}{ Measure } & & \multirow{2}{*}{$\begin{array}{l}\text { Pre-dose } \\
\text { Baseline } \\
\text { score }\end{array}$} & \multicolumn{3}{|c|}{ Post-dose change from baseline score } \\
\hline & & & 1 hour & 3 hours & 6 hours \\
\hline $\begin{array}{l}\text { Quality of } \\
\text { Memory } \\
(\% \times 6)\end{array}$ & $\begin{array}{l}\text { placobo } \\
600 \mathrm{mg} \\
100 \mathrm{mg} \\
1600 \mathrm{mg} \\
\end{array}$ & $\begin{array}{l}415.8613 .50 \\
406.9712 .92 \\
402.9218 .40 \\
405.57+9.70\end{array}$ & $\begin{array}{l}-36.7611 .42 \\
-48.089 .47 \\
-30.24978 \\
-18.8615 .10\end{array}$ & $\begin{array}{l}-46.549 .25 \\
-43.9110 .19 \\
-53.807 .32 \\
-22.0015 .00\end{array}$ & $\begin{array}{l}-67.478 .87 \\
-46.037 .06 \\
-48.8913 .01 \\
-36.0713 .83\end{array}$ \\
\hline $\begin{array}{c}\text { Secondary } \\
\text { Menory } \\
(\% \times 4)\end{array}$ & $\begin{array}{l}\text { placobo } \\
600 \mathrm{mg} \\
100 \mathrm{mg} \\
160 \mathrm{mg}\end{array}$ & $\begin{array}{l}238.5011 .48 \\
230.081002 \\
227.42^{14.48} \\
229.5817 .14\end{array}$ & $\begin{array}{l}-34.2511 .06 \\
-44.179 .10 \\
-30.42906 \\
-21.8313 .31\end{array}$ & $\begin{array}{l}-43.678 .62 \\
-34.33^{866} \\
-43.42^{8.96} \\
-23.17^{14.50}\end{array}$ & $\begin{array}{l}-57.239 .32 \\
-40.00695 \\
-45.0811 .86 \\
-34.421308\end{array}$ \\
\hline $\begin{array}{l}\text { Working } \\
\text { Momory } \\
(\% \times 2)\end{array}$ & $\begin{array}{l}\text { placoboo } \\
600 \mathrm{mg} \\
1000 \mathrm{mg} \\
1600 \mathrm{mg} \\
\end{array}$ & $\begin{array}{r}177.36392 \\
176.884 .80 \\
175.5573 \\
175.9470 \\
\end{array}$ & $\begin{array}{l}-2.51248 \\
-3.92378 \\
0.17460 \\
2.98348 \\
\end{array}$ & $\begin{array}{r}-2.88306 \\
-9.587 .56 \\
-10.387 .58 \\
1.172 \theta 0 \\
\end{array}$ & $\begin{array}{r}-10.24354 \\
-6.032 .55 \\
-3.81440 \\
-1.65271\end{array}$ \\
\hline $\begin{array}{l}\text { Spood of } \\
\text { Memory } \\
\text { (summed } \\
\text { msecs) }\end{array}$ & $\begin{array}{l}\text { plocobo } \\
600 \mathrm{mg} \\
1000 \mathrm{mg} \\
1600 \mathrm{mg}\end{array}$ & $\begin{array}{l}2676.7127 .66 \\
2570.887 .28 \\
2549.980 .35 \\
2671.878 .05\end{array}$ & $\begin{array}{r}-90.356300 \\
1.4137 .70 \\
24.5541 .40 \\
13.5362 .14\end{array}$ & $\begin{array}{r}-163.800 .57 \\
12.5040 .06 \\
71.4860 .60 \\
-58.844 .96 \\
\end{array}$ & $\begin{array}{r}-246.7 \approx 0.35 \\
-141.840 .50 \\
6.469003 \\
-178.350 .34\end{array}$ \\
\hline $\begin{array}{l}\text { Quality of } \\
\text { Attention } \\
(\%)\end{array}$ & $\begin{array}{l}\text { plocebo } \\
600 \mathrm{mg} \\
1000 \mathrm{mg} \\
1600 \mathrm{mg}\end{array}$ & $\begin{array}{l}91.900 .51 \\
91.880 .30 \\
90.900 .76 \\
91.500 .75\end{array}$ & $\begin{array}{r}0.020003 \\
-1.460 .98 \\
-0.291 .12 \\
0.660 .80 \\
\end{array}$ & $\begin{array}{l}-0.610 .00 \\
-1.65079 \\
0.66070 \\
-0.550 .08 \\
\end{array}$ & $\begin{array}{l}-0.960 .52 \\
-1.320 .92 \\
-0.22+.07 \\
-1.400 .67 \\
\end{array}$ \\
\hline $\begin{array}{l}\text { Speed of } \\
\text { Attention } \\
\text { (simmed } \\
\text { msecs) }\end{array}$ & $\begin{array}{l}\text { placobo } \\
600 \mathrm{mg} \\
1000 \mathrm{mg} \\
1600 \mathrm{mg}\end{array}$ & $\begin{array}{r}1030.521 .92 \\
1052 \pi .36 \\
10351903 \\
1040.827 .27\end{array}$ & $\begin{array}{l}14.841378 \\
13.63901 \\
221116.12 \\
37.0911 .46\end{array}$ & $\begin{array}{r}20.8710 .25 \\
-5.12 \times 13.52 \\
28.0613 .75 \\
16.38+1.17\end{array}$ & $\begin{array}{r}9.3814 .32 \\
-6.4115 .80 \\
26.7614 .06 \\
11.281217\end{array}$ \\
\hline
\end{tabular}
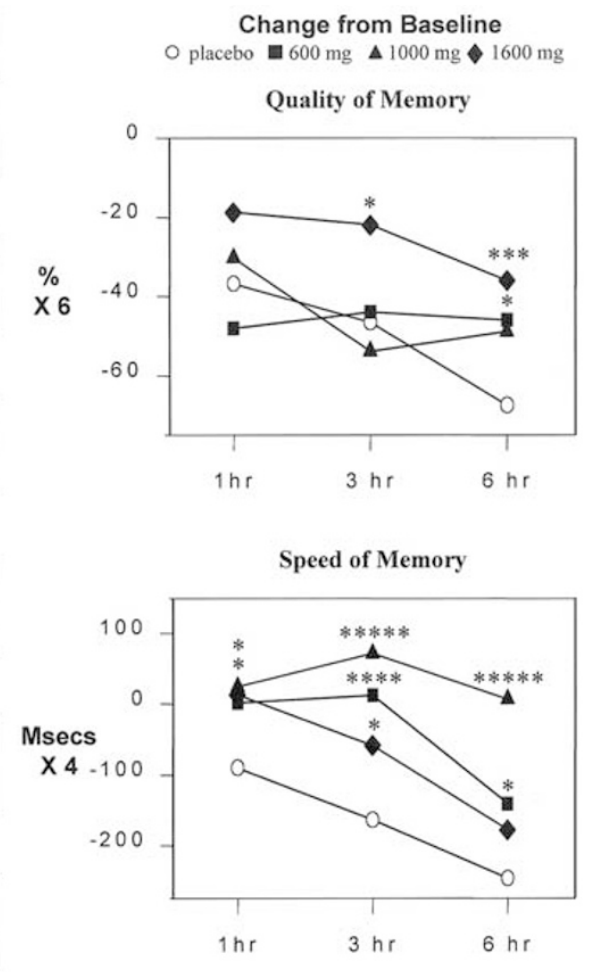

Figure 2 Effects of M. officinalis on cognitive measures, 'quality of memory', 'secondary memory', 'working memory', 'speed of memory', 'speed of attention', and 'accuracy of attention'. The table presents means (with standard errors in italics) of baseline scores and change from baseline scores for each dose of M. officinalis. The graphs represent the change from baseline scores for the outcome measures (also shown as bold in the table) that showed significant differences on the initial ANOVA (planned comparisons: $* P=0.05$; ** $P=0.01$; **** $P=0.005$; ***** $P=0.00 \mathrm{I}$; ***** $P=0.0005$, compared to the corresponding placebo score).

that all three doses were associated with slowing across the timed memory tasks. The lowest dose $(600 \mathrm{mg})$ evinced a significant comparative slowing at the 3 -h $(t(114)=3.4$, $P=0.001)$ and 6 -h $(t(114)=2.02, P=0.046)$ testing sessions. The middle dose $(1000 \mathrm{mg})$ led to reduced speed at all time points $(1 \mathrm{~h}(t(114)=2.2, P=0.03), 3 \mathrm{~h}(t(114)=4.53$, $P=0.00001)$, and $6 \mathrm{~h}(t(114)=4.87, P<0.00001))$, and the highest dose showed a similar effect at the $1-\mathrm{h}(t(114)=2$, $P=0.048)$ and 3 -h $(t(114)=2.02, P=0.046)$ testing sessions.

Reference to the single task outcomes revealed that there was a main effect of treatment on the speed of performing the delayed word recognition task $(\mathrm{F}(3,209)=4.7$, $P=0.003)$ and the spatial memory task $(\mathrm{F}(3,209)=5.57$, $P=0.001)$, with a trend towards the same on the delayed picture-recognition task $(\mathrm{F}(3,209)=2.5, P=0.06)$. Planned comparisons showed decrements for all three doses. These took the form of comparatively reduced speed of performing the spatial memory task at the 3 -h session for the $600 \mathrm{mg}$ dose $(t(114)=2.73, P=0.007)$. Similarly, the highest dose $(1600 \mathrm{mg})$ only showed decrements at a single time point on each of the word-recognition $(1 \mathrm{~h}(t(114)=2.3$, $P=0.023))$ and picture-recognition tasks $(3 \mathrm{~h}(t(114)=2.2$, $P=0.03))$. However, the middle $(1000 \mathrm{mg})$ dose led to comparative decrements at all time points in the speed of performing the spatial memory task $(1 \mathrm{~h}(t(114)=2.27$, $P=0.025), \quad 3 \mathrm{~h} \quad(t(114)=3.18, \quad P=0.002), \quad$ and $6 \mathrm{~h}$ $(t(114)=2.63, P=0.01))$, and at the latter two testing sessions for both the word-recognition $(3 \mathrm{~h}(t(114)=3.04$, $P=0.003)$ and $6 \mathrm{~h}(t(114)=4.6, P=0.00001))$ and picture- recognition tasks $(3 \mathrm{~h}(t(114)=2.3, P=0.023)$ and $6 \mathrm{~h}$ $(t(114)=2.41, P=0.018))$.

Speed of attention factor: There was no effect on this factor, or the component single task outcomes.

Quality of attention factor: There was no effect on this factor, or the component single task outcomes.

Rapid visual information processing task (RVIP): The initial ANOVA showed that there was a main effect of treatment on both the speed $(\mathrm{F}(3,209)=4.13, P=0.007)$ and accuracy in terms of false-positive responses $(\mathrm{F}(3,209)=2.65$, $P=0.05)$ on the RVIP task. Planned comparisons showed that performance was disturbed for both the 600 and $1000 \mathrm{mg}$ doses of melissa. The lower dose was associated with comparatively reduced speed of responding at the $1-\mathrm{h}$ and 6-h testing sessions $((t(114)=2.57, \quad P=0.011)$ and $(t(114)=2.44, P=0.016)$, respectively). This dose also led to increased false-positive responses at $1 \mathrm{~h}$ postdose $(t(114)=2.03, P=0.045)$. The $1000 \mathrm{mg}$ dose resulted in increased false-positive responses at both the 1 - and 3-h testing sessions $((t(114)=2.86, P=0.005)$ and $(t(114)=2.4$, $P=0.018)$, respectively). Baseline and change from baseline data for the RVIP task (\% accuracy, response times, and false positives) are presented in Figure 1.

Subjective mood measures. The initial ANOVA showed that there was no effect on either the 'alert' or 'content' factors derived from the Bond-Lader scales. However, there was a 
significant main effect of treatment on the 'calm' scale $(\mathrm{F}(3,209)=4.95, P=0.002)$. Planned comparisons showed that both 1000 and $1600 \mathrm{mg}$ of $M$. officinalis led to increased ratings of calmness, in comparison to placebo. This effect was evident for the $1000 \mathrm{mg}$ dose at $1 \mathrm{~h}(t(114)=2.24$, $P=0.027)$ and $6 \mathrm{~h}(t(114)=1.99, \quad P=0.049)$, and was sustained throughout the testing day for the $1600 \mathrm{mg}$ dose $(1 \mathrm{~h}(t(114)=2, P=0.047), 3 \mathrm{~h}(t(114)=2.59, P=0.01)$, and $6 \mathrm{~h}(t(114)=2.24, P=0.027))$.

The effects of $M$. officinalis on mood measures are presented in the table and graphs of Figure 3.

\section{DISCUSSION}

The results of the current study confirm both that $M$. officinalis has cholinergic receptor-binding properties, and that the ingestion of single doses can modulate both the mood and cognitive performance of healthy young volunteers in a dose- and time-dependent manner.

Modulation of cognitive performance was reflected both in improved memory performance, and in decrements on the speed of the timed memory tasks and both accuracy and speed of the RVIP task. 'Calmness' was also improved for the higher doses.

While performance following all the three doses was subject to modulation, the general pattern was of more beneficial effects as the dose increased. In line with this, the lowest dose $(600 \mathrm{mg})$ was associated with decrements both on the RVIP in terms of decreased accuracy and in terms of slower performance, and on the timed memory tasks, again in terms of slower performance. At the same time, the $600 \mathrm{mg}$ dose failed to improve subjective ratings on the Bond-Lader scales. The middle dose $(1000 \mathrm{mg})$, on the other hand, showed milder interference on the RVIP, but the severest slowing on the memory tasks. However, these effects were, to a certain extent, offset by increased selfratings of 'calmness'. The highest dose $(1600 \mathrm{mg})$, on balance, was largely beneficial, with comparatively modest (albeit significant at 1 and $3 \mathrm{~h}$ ) slowing of timed memory task performance, but consistent improvements in the accuracy of memory performance and improved ratings of calmness throughout the postdose study period.
This pattern of results shows some intriguing similarities, and differences, to those obtained with the commercial preparation administered in the only previous human study of the cognitive and mood effects of $M$. officinalis (Kennedy et al, 2002b). The most striking similarity is that the decrements seen within the CDR battery in both studies are largely confined to the same tasks, that is, the timed memory tasks, specifically the spatial memory and delayed word-recognition tasks (with the addition in this case of delayed picture recognition). The single proviso to this is that in the previous study, decrements were seen in terms of accuracy, while in the current study, such decrements were manifested as a slowing of performance. Similarly, the dose showing overwhelmingly positive mood effects in the first study led, as here, to increased calmness, a finding that is wholly consistent with contemporary usage of the herb.

The most striking difference then is that the dose-related pattern of results with regard to both the negative cognitive and positive mood effects are in the opposite direction in the case of each study. In the first study, the lowest dose led to the least impaired performance, but improved calmness. However, decrements on the three timed memory tasks increased with dose, and the highest dose was associated with a negative effect on mood, and specifically reduced alertness. In the current study, the performance decrements on the timed memory tasks (and RVIP) were largely restricted to the lower doses, with improvements in mood increasing with dose. These tasks draw on different cognitive, and presumably neural, substrates (eg successful completion of the RVIP requires working memory processes and also draws heavily on executive function). Nevertheless, the most parsimonious explanation for these differences is that they possibly reflect the modulation of shared neural mechanisms. This would suggest that the decreasing decrements with dose on the timed memory tasks following administration of the concentrated manufactured extract, and the increased decrements following the dried leaf, reflect the descending and ascending arms, respectively, of a U-shaped dose-response curve. Similarly, increasing calmness with dose in the previous study and decreasing calmness in the current study may represent the ascending and descending arms of an inverted U-response

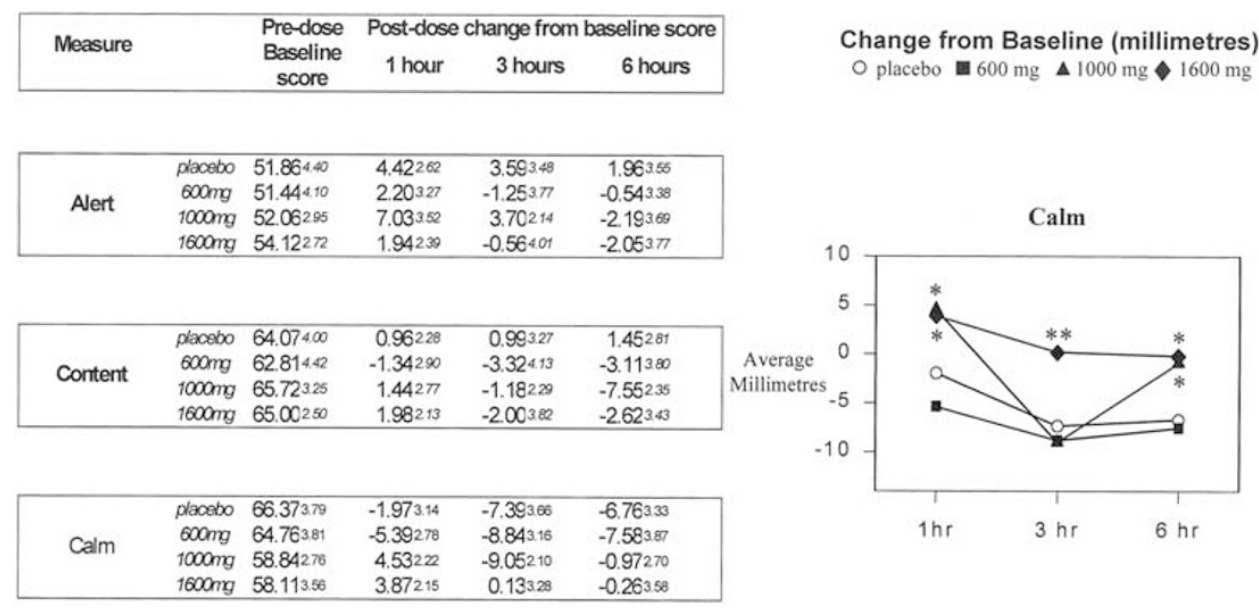

Figure 3 Effects of $M$. officinalis on self-rated mood as measured using Bond-Lader visual analogue scales. The table presents raw scores and change from baseline scores (means with standard errors in italics). The graphs represent the change from baseline scores for the 'calm' factor $(* P=0.05$; $* * P<0.0$ I, compared to the corresponding placebo score). 
curve, respectively. This possibility also suggests that the highest dose in the current study, utilizing dried leaf and therefore providing lower overall dosages of the relevant constituent, and only approaching the herbalist's recommended dose (Bisset and Wichtl, 1994), might have only just reached the therapeutic window in the $M$. officinalis dose-response curves. By the same token, the lowest dose in the first study, using the more concentrated manufactured extract, may have bordered on or exceeded the beneficial dose range. This still leaves open the question of the added benefits of doses of dried leaf above the $1600 \mathrm{mg}$ utilized here, and doses of the concentrated extract below $300 \mathrm{mg}$.

The apparent contradiction between somewhat impaired speed on memory tasks and improved memory performance for the highest dose (given that this dose's relatively mild impairment on the former, and specific improvement on the immediate word recall task argue against this being a 'speed-accuracy' tradeoff) also suggests that the decrements seen in both studies are not necessarily memory specific. An explanation that would satisfy Occam's razor is that the tasks involved are simply the most cognitively demanding tasks within the battery. Reference to the reaction times for the relevant tasks confirms this, as do the similar decrements that were seen on the nonmemory, but equally demanding, RVIP.

If it is accepted that the decrements in performance are not memory specific and, given the lack of nicotinic receptor binding in the first study (Kennedy et al, 2002b), are probably not attributable to direct interaction with nicotinic receptors, then the improved memory performance can be viewed as being attributable to a separate mechanism. Naturally, given the rationale of the study, it is tempting to suggest that the improved secondary memory performance (in the absence of working memory effects) for the highest dose is directly attributable to the demonstrated cholinergic receptor-binding properties of the dried leaf used in the present study. Such a pattern of results is broadly consistent with demonstrations of cholinergic modulation of long-term memory (Drachman and Leavitt, 1974; Peterson, 1977), but not working memory (Rusted and Warburton, 1989). Given that the treatments in both this and the former study possessed measurable muscarinic receptor-binding properties, it is possible that the decrements on the cognitively demanding timed tasks are attributable to interaction with these receptors. However, it is equally likely that this specific effect is mediated through another mechanism, and, of course, interaction with other neurotransmitter systems cannot be ruled out. One speculative possibility is that the decrements could be related to modulation of noradrenergically mediated vigilance, which has been shown to preferentially disrupt tasks that require a more difficult sensory discrimination. This proposition could account for decrements on the more difficult tasks, while allowing the possibility that a noradrenergic reduction in neuronal 'noise' (see Scholey, 2002) might favor the attention to and performance of simple tasks, as was seen in dose-specific improved performance on the cognitively underloaded attention tasks in the former study (Kennedy et al, 2002b), and a lack of decrements on these tasks in both studies. Noradrenergic modulation may also be implicated in the improved 'calmness' seen following M. officinalis. The possibility that
M. officinalis interacts with a number of neurotransmitter systems deserves further investigation. Indeed, the wider question of how the manufacturing process defines the active properties of herbal extracts, and thereby the behavioral consequences of their administration, is one that has ramifications for all herbal supplements. The clear demonstration of differential patterns of both in vitro properties and behavioral consequences following the manufactured extract (Kennedy et al, 2002b) and the dried leaf employed in the current study certainly suggests that this matter deserves further research attention.

This study shows, for the first time, a profile of acute cognitive effects in an extract of $M$. officinalis with demonstrable cholinergic activity, while the chosen extract had relatively high binding levels compared with other extracts both here (Table 1) and elsewhere (Perry et al, 1996; Wake et al, 2000). As whole leaf extracts contain many potentially neuroactive constituents (many as yet unidentified), it is not yet possible to meaningfully quantify these binding properties on a simple 'activity per weight' basis. It is clearly of great interest to identify such active agents.

On the broader question of a possible medicinal role for $M$. officinalis, it is notable that the results evinced here support the suggestion that $M$. officinalis may eventually have a role to play in the treatment of dementia (Perry et al, 1996, 1999). What is particularly interesting about melissa's potential as a treatment is that the pharmacological arsenal for Alzheimer's disease currently lacks a well-tolerated cholinergic receptor agonist. It is conceivable that the cholinergic effects of $M$. officinalis may be of value to those individuals with a loss of nicotinic receptors. $M$. officinalis also has other properties that might recommend it as a candidate treatment. The first is that advanced Alzheimer's disease commonly involves severe agitation and mood disturbance. In line with the results of both this and the former study (Kennedy et al, 2002b), and both traditional and contemporary usage of $M$. officinalis, extracts of the plant would seem to have a specific calming or mildly sedative effect. A practical application for this has already been demonstrated in the double blind, placebo-controlled demonstration (Ballard et al, 2002) of reduced agitation and social withdrawal, and increased time spent in constructive activities in an $M$. officinalis aromatherapy group of sufferers from advanced Alzheimer's disease. The results of this study also raise the possibility that beneficial doses of melissa may have potential efficacy in the attenuation of the cholinergic decrements observed in aging as well as in states of delirium, such as those sometimes associated with anticholinergic drugs (Ashton, 2002). The other potential beneficial property of the herb is that, despite a history of usage stretching into millennia, there are no reports of detrimental side effects, even of an anecdotal nature. On the other hand, as the use of herbal preparations, including nontraditional formulations, increases, there is a growing need for systematic toxicological data, especially regarding potential interactions with other drugs.

The current study raises a number of issues and questions. The most pertinent is whether increasing the dose of $M$. officinalis leaf above the maximum used here will confer additional benefits, and how high the dose can be taken before performance and mood become disturbed. The question of chronic effects, and specifically chronic effects 
in cholinergically challenged populations, also requires elucidation.

Similarly, a concurrent systematic study of melissa extracts, which extends our knowledge of their bio-activity beyond the cholinergic binding demonstrated here, also deserves to be addressed.

\section{REFERENCES}

Ashton H (2002). Delerium and hallucinations. In: Perry EK, Ashton H, Young AH (eds). Neurochemistry of Consciousness. Benjamins: Amsterdam. pp 181-203.

Ballard C, O'Brien J, Reichelt K, Perry E (2002). Aromatherapy as a safe and effective treatment for the management of agitation in severe dementia: the results of a double blind, placebo controlled trial. J Clin Psychiatry 63: 553-558.

Bisset NG, Wichtl M (1994). Herbal Drugs. Medpharm: Stuttgart.

Bond A, Lader M (1974). The use of analogue scales in rating subjective feelings. Br J Psychol 47: 211-218.

Carnat AP, Carnat A, Fraisse D, Lamaison JL (1998). The aromatic and polyphenolic composition of lemon balm (Melissa Officinalis L. subsp. Officinalis) tea. Pharm Acta Helvetiae 72: 301-305.

Cerny A, Schmid K (1999). Tolerability and efficacy of valerian/ lemon balm in healthy volunteers: a double-blind, placebocontrolled, multicentre study. Fitoterapia 70: 221-228.

Coghan T (1584). The Haven of Health, (Cited in Perry et al 1999).

Drachman DA, Leavitt J (1974). Human memory and the cholinergic system. Arch Neurol 30: 113-121.

Dressing H, Riemann D, Löw H, Schredl M, Reh C, Laux P et al (1992). Insomnia: are valerian/balm combinations of equal value to benzodiazepine? Therapiewoche 42: 726-736.

Ebert U, Siepmann M, Oertel R, Wesnes K, Kirch W (1998). Pharmacokinetics and pharmacodynamics of scopolamine after subcutaneous administration. J Clin Pharmacol 38: 720-726.

Ellman GK, Courtney KD, Andres V, Featherstone RM (1961). A new and rapid colorimetric determination of acetylcholinesterase activity. Biochem Pharmacol 7: 88-95.

Evelyn J (1699). Acetaria. London. (cited in Le Strange, 1997).

Grieve M (1931). A Modern Herbal. Jonathan Cape: London. (reprinted by Penguin Books Ltd, London, 1980).

Hohmann J, Zupko I, Redei D, Csanyi M, Falkay G, Mathe I et al (1999). Protective effects of the aerial parts of Salvia Officinalis, Melissa Officinalis and Lavandula angustifolia and their constituents against enzyme-dependent and enzyme-independent lipid peroxidation. Planta Med 65: 576-578.

Kennedy DO, Scholey AB, Wesnes KA (2000). The dose dependent cognitive effects of acute administration of Ginkgo biloba to healthy young volunteers. Psychopharmacology 151: 416-423.

Kennedy DO, Scholey AB, Wesnes KA (2001a). Differential, dosedependent changes in cognitive performance and mood following acute administration of Ginseng to healthy young volunteers. Nutr Neurosci 4: 295-310.

Kennedy DO, Scholey AB, Wesnes KA (2001b). Differential, dose dependent changes in cognitive performance following acute administration of a Ginkgo biloba/Panax ginseng combination to healthy young volunteers. Nutr Neurosci 4: 399-412.

Kennedy DO, Scholey AB, Tildesley NTJ, Perry EK, Wesnes KA (2002b). Modulation of mood and cognitive performance following acute administration of single doses of Melissa officinalis (Lemon Balm). Pharmacol Biochem Behav 72: 953-964.

Kennedy DO, Scholey AB, Wesnes KA (2002a). Modulation of cognition and mood following administration of single doses of Ginkgo biloba, Ginseng and a Ginkgo/Ginseng combination to healthy young adults. Physiol Behav 75: 1-13.

Keppel G (1991). Design and Analysis. Prentice Hall: New Jersey. Kirk RE (1968). Experimental Design: Procedures for the Behavioural Sciences. Brooks/Cole: Belmont, CA.
Koch-Heitzmann I, Schultze W (1988). 2000 Jahre Melissa officinalis. $Z$ Phytother 9: 77-85.

Kommission E Monograph (1984). Melissenblätter; Bundesanzeiger 05.12.

Le Strange R (1997). A History of Herbal Plants. Morrison \& Gibb: London.

Mantle D, Eddeb F, Pickering A (2000). Comparison of relative antioxidant activities of British medicinal plant species in vitro. $J$ Ethnopharmacol 72: 47-51.

Moss MC, Scholey AB, Wesnes KA (1998). Oxygen administration selectively enhances cognitive performance in healthy young adults: a placebo-controlled double-blind crossover study. Psychopharmacology 138: 27-33.

Mulkens A, Stephanou E, Kapetenadis I (1985). Heterosides a genines volatiles dans les feuilles de Melissa Officinalis L. (lamiaceae). Pharm Acta Helvetiae 60: 276-278.

O'Neill WM, Hanks GW, White L, Simpson P, Wesnes K (1995). The cognitive and psychomotor effects of opioid analgesics I. A randomised controlled trial of single doses of dextropropoxyphrene, lorazepam and placebo in healthy subjects. Eur J Clin Pharmacol 48: 447-453.

Perry N, Court G, Bidet N, Court J, Perry E (1996). European Herbs with cholinergic activities: potential in dementia therapy. Int $J$ Geriatric Psychiatry 11: 1063-1069.

Perry EK, Pickering AT, Wang WW, Houghton PJ, Perry NSL (1999). Medicinal plants and Alzheimer's disease: from ethnobotany to phytotherapy. J Pharm Pharmacol 51: 527-534.

Peterson RC (1977). Scopolamine induced learning failures in man. Psychopharmacology 52: 283-289.

Rote liste (2001). CMDI/Boehringer Ingelheim.

Rusted JM, Warburton DM (1989). Cognitive models and cholinergic drugs. Neuropsychobiology 21: 31-36.

Scholey AB (2002). Attention. In: Perry EK, Ashton H, Young A (eds). Neurochemistry of Consciousness. John Benjamin: Amsterdam. pp 43-63.

Scholey AB, Moss MC, Neave N, Wesnes KA (1999). Cognitive performance, hyperoxia and heart rate following oxygen administration in healthy young adults. Physiol Behav 67: $783-789$.

Soulimani R, Fleurentin J, Mortier F, Misslin R, Derrieu G, Pelt JM (1991). Neurotropic action of the hydroalcoholic extract of Melissa officinalis in the mouse. Planta Med 57: 105-109.

Wagner H, Sprinkmeyer L (1973). ber die pharmakologische Wirkung von Melissengeist. Dtsch Apoth Ztg 113: 1159-1166.

Wake G, Court J, Pickering A, Lewis R, Wilkins R, Perry E (2000). CNS acetylcholine receptor activity in European medicinal plants traditionally used to improve failing memory. J Ethnopharmacol 69: 105-114.

Wesnes K, Anand R, Simpson P, Christmas L (1990). The use of the scopolamine model to study the potential nootropic effects of aniracetam and piracetam in healthy volunteers. J Psychopharmacol 4: 219-232.

Wesnes KA, Faleni RA, Hefting NR, Hoogsteen G, Houben JJG, Jenkins E, Jonkman JHG, Leonard J, Petrini O, van Lier JJ. (1997). The cognitive, subjective, and physical effects of a Ginkgo biloba 1 Panax ginseng combination in healthy volunteers with neurasthenic complaints. Psychopharm Bull 33: 677-683.

Wesnes KA, Ward T, McGinty A, Petrini O. (2000). The memory enhancing effects of a Ginkgobiloba/Panax ginseng combination in healthy middle aged volunteers. Psychopharmacology 152: 353-361.

Wesnes K, Warburton DM (1984). Effects of scopolamine and nicotine on human rapid information processing performance. Psychopharmacology 82: 147-150.

Wong AHC, Smith M, Boon HS (1998). Herbal remedies in psychiatric practice. Archive of General Psychiatry 55: 10331044. 